\title{
Experimental approaches to the prophylaxis and treatment of ischaemic heart disease
}

\author{
J. D. FitzGerald \\ M.B., M.R.C.P. \\ Head of Pharmacology, Imperial Chemical Industries, \\ Mereside, Alderley Park, Macclesfield, Cheshire
}

\section{Summary}

This paper describes some of the basic hypotheses on which our research in the cardiovascular field has been based. The difficulties and shortcomings of the experimental models used and our reliance on guidance from clinical science has been emphasized. The properties, effects and mode of action of the drugs resulting from our cardiovascular research have been described.

\section{Introduction}

The purpose of this paper is to describe our research aims and their implementation in the field of ischaemic heart disease. The research programme is divided into two areas. Firstly, the discovery of a means of controlling the development of coronary artery disease, and secondly the devising of agents that would control the complications of establishect coronary artery disease (Fig. 1). There are twor requirements for effective research in the field of coronary artery disease. In the first instance, there is a need for reliable animal models of the disease and its complications. Whilst many forms of experimental atherosclerosis are available, their relevancE to the human disease is debatable, particularly in relation to the development of therapeutic agentso The second requirement is an agreed understanding. of the pathogenesis of coronary artery disease its attendant complications. Unless clinicians delineate realistic therapeutic goals, based of knowledge of the causative mechanisms underlying the disease, then experimental research may easils proceed along misguided lines.

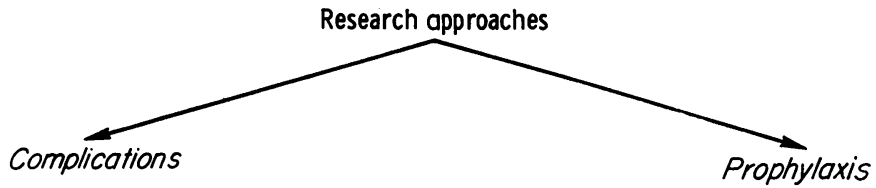

(a) Angina pectoris

(b) Myocardial infarction i.arrhythmias

ii. ' pump failure'

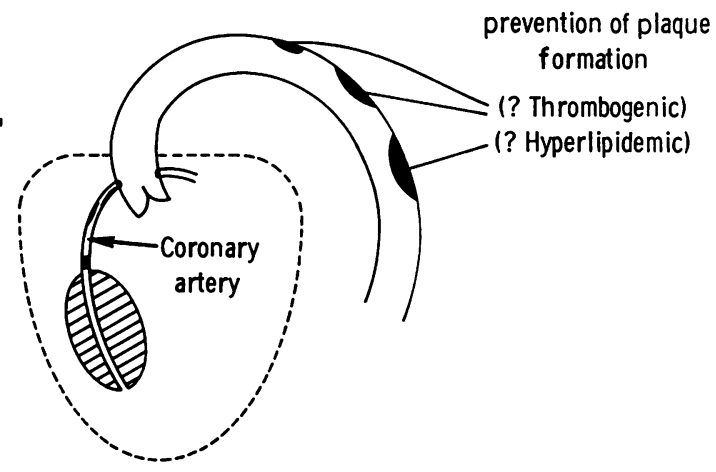

FIG. 1. The basis of the separation of experimental research in ischaemic heart disease. 


\section{Prophylaxis of coronary artery disease}

The experimentalist in this field is in the difficult position of wishing to devise an experimental model to test synthetic substances whilst there is disagreement as to what a particular animal model really means in terms of human disease, what therapeutic target is worthwhile, and what type of agent might be devised to achieve such a target. Whilst the mechanism of formation of the atherosclerotic plaque is debatable, clinical and epidemiological research suggests that certain factors predispose to plaque formation (Katz \& Stamler, 1953). An obvious approach to the problem of the atherosclerotic plaque could be to delineate all the factors that favour its growth, and attempt to attenuate or even reverse the trend. In 1955, when our research in this field started, the factor that was most widely considered worthy of control was elevated serum lipids, particularly serum cholesterol. The association between hyperlipidaemia and ischaemic heart disease is based on four types of observation: (1) that arterial lesions contain lipid, (2) that induced hyperlipidaemia in animals leads to arterial lesions rich in lipids, (3) that patients with the symptom complex of ischaemic heart disease often have abnormal serum lipid levels, and (4) that hypercholesterolaemia at least is associated with increased risk of developing ischaemic heart disease (Oliver, 1967a). At that time, our research aim, therefore, was to discover an agent that would lower serum cholesterol and triglycerides effectively, and cause no serious side effects. Such an agent should meet most of the following requirements: (a) it should have a sustained and consistent effect in reducing elevated serum cholesterol and triglycerides or more correctly, it should consistently lower the $\mathrm{SF}_{0-20}$ and $\mathrm{SF}_{20-400}$ lipoprotein fractions, (b) this lowering of the serum lipids should be associated with a lowering of the accumulation of lipids in tissues, (c) there should be an increase in the excretion of neutral sterols in the stool, (d) the agent should not alter the patient's way of living, (e) there should be few toxic effects associated with the achievement of the hypolipidaemic action, (f) there should be few side-effects, (g) precursors of cholesterol should not accumulate in the body, (h) an understanding of the mode of action of the drug is necessary. The reason for laying down such stringent requirements is that the final aim of treatment may be to give the agent to healthy hyperlipidaemic individuals who are assumed to have a greater than usual risk of developing vascular disease and who may therefore need to take the drug for the rest of their lives.

More recently, additional requirements have been laid down. In addition to demonstrating that an * Clofibrate ('Atromid-S'-ICI) is the ethyl ester of chlorophenoxyisobutyric acid (CPIB). agent must lower elevated serum lipids effectively and safely, it is necessary to show that, if it is given in the pre-symptomatic or established phases of ischaemic heart disease, it alters the mortality from coronary heart disease. Some knowledge of its effect on the atherosclerotic plaque is also necessary.

\section{Clofibrate*}

Clofibrate meets many of the requirements laid down above, though naturally answers are still awaited from many of the studies with this compound. The activity of clofibrate was discovered in 1955 by Thorp, whilst examining a series of aryloxy isobutyrates with the following basic chemical structure (Fig. 2). Thorp showed that they all possess a novel type of hypolipaemic activity in experimental animals (Thorp, 1955). In normal rats and dogs the serum cholesterol was lowered by $60-70 \%$ compared to that of controls, following administration of these compounds, and the response was maintained for as long as the compound was administered. The cholesterol returned to normal levels on stopping treatment. Initially, therefore, the testing procedure was simply to determine the effect of these drugs on serum cholesterol in a variety of animals. One compound, the $p$-chlorophenol aryloxyisobutyric acid (CPIB*) was selected for clinical evaluation. Studies in monkeys showed that the addition of androsterone potentiated the hypolipidaemic action of CPIB and therefore the first studies in man were carried out with clofibrate in combination with androsterone. Subsequently, it was found that an equivalent hypolipidaemic effect could be achieved in man without the addition of androsterone (Oliver, 1963).

The effect of CPIB in man is to reduce elevated levels of serum lipoproteins, particularly the $\mathrm{SF}_{20-400}$ fraction and to a lesser extent the $\mathrm{SF}_{\mathbf{0}-20}$ fraction. Studies in a mixed population of patients with coronary artery disease show that elevated serum

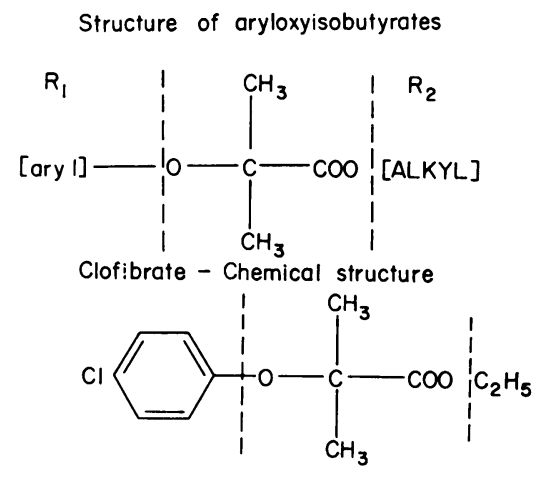

FIG. 2. The structure of aryloxyisobutyrates and clofibrate. 
cholesterol levels are reduced by $15-30 \%$ and elevated serum triglyceride levels by $30-40 \%$ (Oliver, 1967b). These effects persist for as long as treatment continues, and no escape is observed in patients who respond adequately. In addition, clofibrate reduces alimentary lipaemia, and increases lipoprotein lipase activity (Hood, Bedding \& Corlander, 1963). Serum free fatty acids are lowered, but are still responsive to catecholamine stimulation. Clofibrate does not cause accumulation either in blood or tissues of unsaturated precursors of cholesterol such as desmosterol, and it brings about a reduction in the total cholesterol pool (Nestel, Hisch \& Couzens, 1965; Hellman et al., 1963). This is accompanied by an increased biliary excretion of neutral sterols (Mitchell, Truswell \& Brontestewart, 1967). Raised plasma fibrinogen is reduced by clofibrate, and decreased fibrinolytic activity is enhanced. Platelet stickiness, platelet turnover and platelet survival times are altered towards normal values (Oliver, 1967b). In clinical terms, visible tissue deposits such as lipaemic exudates in the retina of diabetics with retinopathy, or skin xanthomata may regress following treatment with clofibrate for 6-12 months (Duncan et al., 1968; Mishkel, 1967). The initial regression may be achieved without a marked reduction in the serum cholesterol, which suggests that it may take several months to reduce a large cholesterol pool. Oliver (1967) has suggested that the principal indications currently for the use of clofibrate are (1) patients with hypercholesterolaemia and hypertriglyceridaemia with or without xanthomata, (2) patients with fasting latescent plasma, (3) patients with hypercholesterolaemia with or without a familial predisposition to vascular disease, (4) diabetic patients with lipaemic diabetic retinopathy, in order to prevent further deterioration in visuaf acuity.

\section{Mode of action of clofibrate}

Any explanation of the mode of action of clos? fibrate must take into account the following observao tions. (1) Clofibrate does not decrease cholesterof synthesis in the liver when added to liver slices $i \overline{\bar{m}}$. vitro. This suggests, therefore, that it does not have $\mathbb{8}$ direct action on cholesterol synthesis at the hepatio level (Avoy, Swyrd \& Gould, 1965; Thorp \& Waring, 1962). (2) Clofibrate does not lower serunP cholesterol in animals which have been thyroidec tomized (Westerfeld, Richert \& Ruegamer, 1968). (3) The volume distribution of CPIB shows thas $96-98 \%$ is confined to the albumin space which is $8-12 \%$ of the total body weight. It is bound to the anionic binding sites of albumin. (4) In experimental animals, CPIB is not detected in hepatic bile, and most of an oral dose is excreted in the urine as the glucuronide (Thorp, 1963). The problem, therefore? is to explain how an organic acid that is fully ionized in plasma, and is highly albumin-bound, that is excreted as the glucuronide via the kidney and is nof metabolized in the body, can exert such a wide्ष variety of effects (Fig. 3). The multi-system of effeets? of CPIB can be explained on the hypothesis tPate physiologically important albumin-bound en genous acids are displaced from albumin by $\mathrm{CP} \overline{\mathrm{B}}$ Thus the continuous administration of CPIB resuft? in a new equilibrium state in which these endogenous acids are either displaced to weaker ionic binding sites on albumin, or displaced altogether fromp albumin to cause a small increase in the concentra tion of 'free form' in the circulation. The free form?

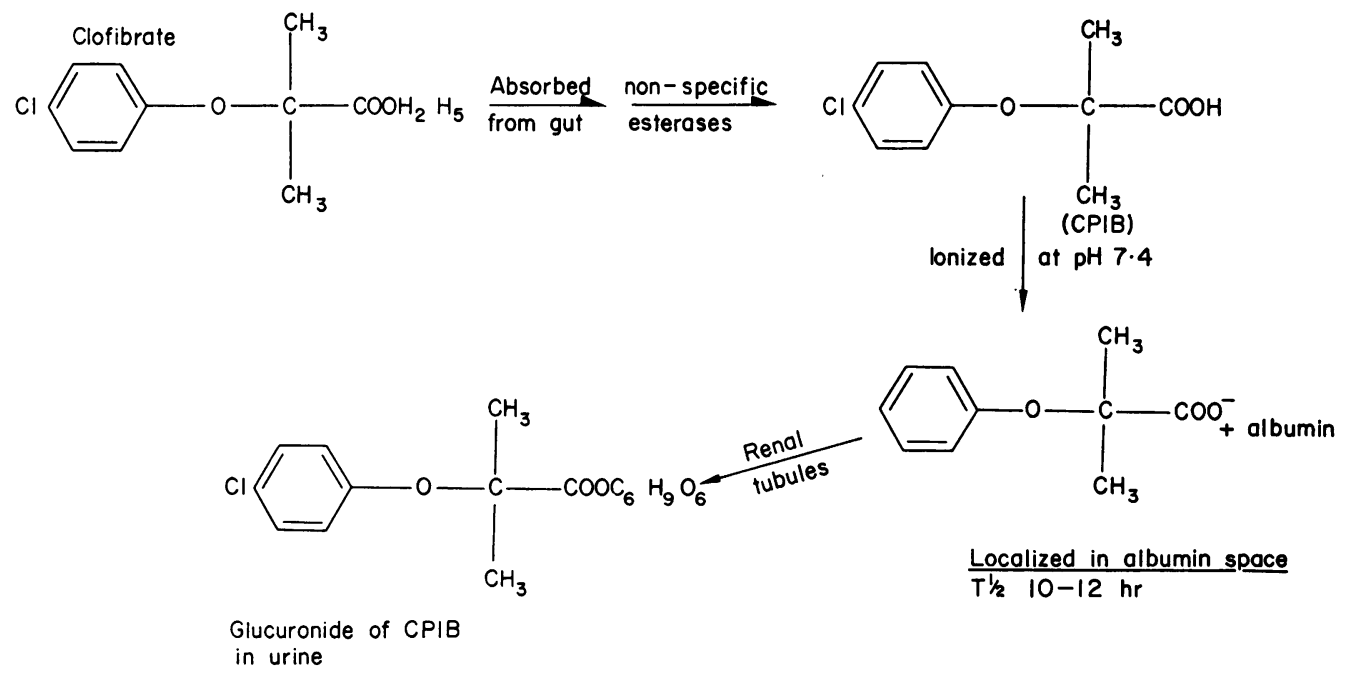

FIG. 3. Metabolism of clofibrate. 
of these substances is responsible for their physiological effects. Physiologically important substances that are bound to albumin, which have been shown to be displaced by clofibrate, are thyroxine and its metabolites, free fatty acids, and 17-ketosteroid sulphates as well as pyridoxal phosphate and tryptophan.

There is much experimental work to support this hypothesis.

\section{Clofibrate and thyroxine}

Chang et al. (1967) have confirmed that clofibrate depresses the thyroxine binding to human prealbumin at a concentration of $6 \times 10^{-3} \mathrm{M}$. Thyroxinebinding globulin is unaffected. Studies by Thorp (Thorp \& Waring, 1962), and more recently by Westerfield et al. (1968) have shown that clofibrate increases the concentration of radio-labelled thyroxine in the rat liver by $40 \%$. There is no increase in the metabolic rate or alteration in thyroid function in these rats. In the thyroidectomized rat, the action of clofibrate on serum cholesterol is abolished. Furthermore, it has been shown that in the rat, the maximal effect of CPIB on the serum cholesterol corresponds with the period of maximal thyroid adrenocortical function. Clofibrate causes an increase in the weight of the liver in the rat and monkey, which is due to increased synthesis of hepatic protein. This is accompanied by a reduction in hepatic glycogen (Platt \& Thorp, 1966). These changes are identical with those observed when thyroxine alone is administered. Studies by Harrison \& Harden (1966) in hypercholesterolaemic patients with severe myxoedema showed that the serum cholesterol was unaffected by clofibrate until a small supplement of thyroxine is added. The hypolipidaemic effect of thyroxine treatment is significantly enhanced by the simultaneous administration of clofibrate. If thyroxine alone is subsequently withdrawn, a rebound of serum cholesterol to the pretreatment level, or higher, occurs.

Apart from its effects on thyroxine distribution, clofibrate also reduces the transport of free fatty acids from the fat organ to the liver. Barrett in our laboratories has shown that in vitro, CPIB will reduce the rate of free fatty acid release from epididymal fat pads incubated in plasma, as well as reduce the peak levels of free fatty acids following the injection of adrenaline and noradrenaline (Barrett, 1969a). It also abolishes the increase in cholesterol and phospholipids following ACTH stimulation in dogs. These observations suggest that part of the hypolipidaemic action of CPIB is due to depression of free fatty acid transport (Thorp, personal communication).

In summary, it seems that clofibrate acts primarily by displacing physiologically important substances from anionic binding sites on albumin. As a result, there is an increased uptake of thyroxine by the liver. The increased hepatic thyroxine activity causes an increase in protein synthesis. The accompanying reduction in hepatic glycogen increases the hepatic requirement for an alternative energy substrate, i.e. free fatty acids. However, in the presence of clofibrate, there is a depression of circulating free fatty acid levels. The combined effects of a diminished supply of free fatty acids to the liver and an increase in concentration of hepatic thyroxine, results in a marked drop in circulating levels of $\mathrm{SF}_{20-400}$ lipoproteins which is the most marked and consistent effect of clofibrate in man. This summary of the mode of action of clofibrate is almost certainly incomplete. Space does not permit a consideration of the possible role of other important substances such as pyridoxal phosphate, androsterone sulphate, dehydroepiandrosterone sulphate and tryptophan.

\section{Subsequent developments}

Some scepticism exists in regard to this view of the mechanism of action of clofibrate. If the theory is true, then it should be possible to discover other agents which also lower serum lipids because they displace physiologically active substances from albumin. In the past 5 years, our experimental approach to the lowering of serum lipids has been to test drugs in vitro. A search was made for compounds displaying a greater selectivity and intensity of effect on the binding of thyroxine to albumin and prealbumin than that of clofibrate. Furthermore, we wished to discover compounds with a greater degree of persistence in vivo than clofibrate, so that a lower daily dosage could be used. The first tests consisted of studies of the water solubility and half-life, in the rat, of candidate compounds of the aryloxyisobutyrate series. It was found that diminished water solubility was accompanied by an increase in the in vivo half-life.

Experiments were then carried out to determine the effects in vitro of selected compounds on the albumin binding of thyroxine. It was found that the compound ICI 54,856 was more effective than CPIB in increasing the amount of free thyroxine in an in vitro albumin-thyroxine system.

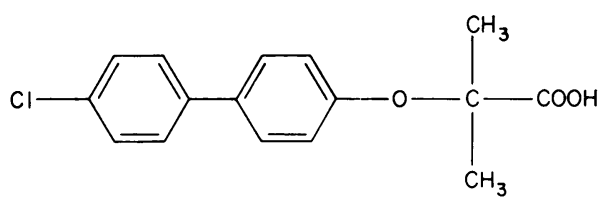

The methyl ester of ICI 54,856 has been taken forward for both animal and human studies. Its action is similar to that of clofibrate, but because of its increased persistence, it is effective at about 
$1 / 100$ th of the dose of clofibrate in lowering blood cholesterol in rat, dog and man. Its half-life in man is 30-40 days. An effective dose in man is $0.1 \mathrm{mg} / \mathrm{kg}$, giving a circulating level of $60 \mu \mathrm{g} / \mathrm{ml} .60-90 \%$ of ICI 54,856 is excreted by the kidney, partly as the free acid and partly as the glucuronide conjugate. Preliminary clinical trials with this novel compound show that it not only lowers the $\mathrm{SF}_{20-400}$ lipoprotein fraction effectively, but also the $\mathbf{S F}_{\mathbf{0 - 2}}$ fraction, which in certain cases is resistant to CPIB treatment. (Barrett, 1969a). This drug is, however, in very early stages of clinical evaluation, and it is still in the experimental phase. It illustrates how an understanding of the mode of action of a drug can lead to further discoveries and that careful in vitro studies can be of predictive value for drug action in man.

\section{The treatment of the complications of coronary artery disease}

\section{Angina pectoris}

There is no animal model for the study of angina pectoris, because it is a symptom and therefore is peculiar to man. Any experimental approach must be related to clinical experience. It is widely accepted that anginal pain results from a disproportion between myocardial work and myocardial oxygen supply. Most experimental effort in the past has been devoted towards developing therapeutic agents which will increase myocardial blood flow. Whilst substances with potent dilating effects have been found, their clinical success appears to have been limited. Unless the obstruction to blood flow in diseased coronary arteries can be removed, it is probably more rational to attempt to improve the mechanical efficiency of the pump, rather than to improve blood flow through diseased arteries. All therapy for angina pectoris aims at reducing the work of the heart for a given external work-load, and no drug has been discovered that permits more total cardiac work to be done before pain. Thus, both weight-loss and trinitrin exert their beneficial effects in angina by diminishing the work of the heart. Initially, trinitrin was thought to act primarily by coronary vasodilatation, but this is not now considered to be the primary mode of action (Gorlin et al., 1959). Cervical sympathectomy also lowers the work of the heart as shown by Apthorp, Chamberlain \& Hayward (1964). In their group of eight anginal patients who underwent bilateral cervical sympathectomy for severe angina pectoris, several patients increased their exercise tolerance two to three-fold following this operation. Similarly, Lindgren (1950) has reviewed the effects of cervical sympathectomy in eighty anginal subjects, and shown that $52 \%$ showed marked or moderate improvement through this operation.
These studies emphasize the role of endogenou catecholamines in increasing cardiac work.

Black in our laboratories initiated studies aime@ at specifically interfering, by chemical means; with catecholamine activity on the heart. It wa hoped that an agent could be discovered whicb would diminish the effects of catecholamines in irf creasing cardiac work in those patients with impaire myocardial blood supply (Black, 1967). A clue as to the type of chemical structure to be sought was pros vided by the discovery of Powell \& Slater (1958), that the dichloro analogue of isoprenaline would block the effects of catecholamines on the heart. Though dichloroisoprenaline was introduced to clinicat studies, there is no evidence that it was studied ig angina pectoris. Thus it was Black's hypothes which really provided the impetus rather than this discovery of dichloroisoprenaline. The first effective agent discovered was pronethalol ('Alderlin', ICI It was introduced into clinical trial specifically to determine whether an agent which prevented the action of catecholamines on the heart would be of benefit in angina pectoris (Black \& Stephenson 1962). It was shown to increase exercise tolerance if angina pectoris, and also to improve the anginat state clinically (Dornhorst \& Robinson, 1 Alleyne et al., 1963) Subsequently, pronethalol gas withdrawn because it was found to cause lymp通o= mata in the thymus of certain strains of mice- ty was replaced by propranolol ('Inderal', ICI) which has a different chemical structure and is more poten (Black, Duncan \& Shanks, 1965).

\section{Mode of action in angina pectoris}

Stimulation of cardiac beta-receptors results in a $\overrightarrow{\overrightarrow{\underline{Q}}}$ increased rate and force of myocardial contraction? as well as speed of conduction within the heart. A a result there is an increase in the oxygen consumption of the heart. In the healthy heart, blood flow to the myocardium is not a limiting factor, and therefore the heart is able to increase its work withou incurring any damage. However, where the blood supply is limited, then there is reason to supposg that benefit may accrue from attenuating changes is the rate and force of myocardial contraction.

The mode of action of propranolol in reducing cardo iac work is complex. The more important features are (1) reduction in heart rate, (2) reduction in the speed $\dot{\alpha}^{\circ}$ myocardial fibre shortening, (3) possibly a reductiono in after-load. All these effects will reduce myocardia oxygen demand. They may be offset if the hearf increases in size, as is associated with cardiac slowing and a reduction of myocardial contractility. FurtherE more, there may be an increase in the systolic ejection time. An increase in either of these parameters wilf increase myocardial oxygen demand. It is thus not possible to predict which action will predominate if 
an individual patient, so that some will improve and others may not (Fig. 4). Intensive study of propranolol in angina pectoris indicates that many patients with angina pectoris improve their exercise tolerance, reduce their daily incidence of anginal pain, and diminish their requirements for glycerol trinitrate (Amsterdam, Wolfson \& Gorlin, 1968; Gianelly et al., 1967; Ginn \& Orgain, 1966).

It has been suggested that propranolol works in angina pectoris by a means other than beta-receptor blockade (Grandjean, 1967; British Medical Journal, 1969). Propranolol possesses the additional pharmacological property of membrane-stabilization "or local anaesthesia (Vaughan Williams, 1966; Fitzgerald, 1960). Hence, it has been suggested that this property, by causing non-specific myocardial depression, will improve the anginal state. Clinical evidence that this is not so has been provided by the study of Robinson's group in St George's Hospital (Wilson et al., 1969). They have compared the dextro-isomer of propranolol which has equivalent membrane-stabilizing properties, but no beta-blocking properties, with racemic propranolol, which possesses both properties. They showed that dexpropranolol, like saline, did not increase exercise tolerance in eight anginal patients, whilst racemic propanolol did do so. It is now very probable that the possession of membrane-stabilizing properties is irrelevant to the mode of action of racemic propranolol in the clinical dose range in which it is used (Barrett, 1969; Fitzgerald, unpublished observations).

Once the clinical effectiveness of propranolol had been established, the problem then arose as to what

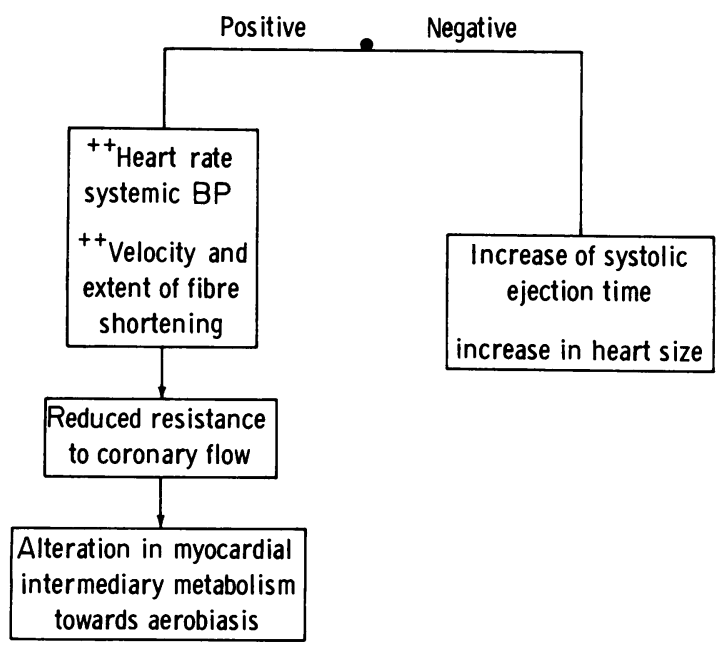

FIG. 4. Schematic representation of wanted and unwanted haemodynamic effects of beta blocka de in angina pectoris. further discovery would be clinically desirable. Propranolol blocks other clinically important betareceptors, particularly those in the lung and those subserving certain metabolic responses. A legitimate therapeutic aim might be an increase in selectivity of activity, so that only beta receptors in the heart were blocked. Furthermore, a compound might be discovered which possessed no membrane stabilizing or local anaesthetic properties. In order to discover such a compound, the following screening procedure was employed. Initially all candidate drugs were studied for their effects in antagonizing isoprenaline on the heart, peripheral blood vessels and lungs. The aim of these primary tests was to separate an effect on the heart from the effects on the lung and blood vessels. If a likely compound was found, it was then studied for its effects on the spike potential in the isolated frog nerve and also for its effects on intra-cardiac conduction. If the candidate compound still seemed interesting, its effects on lipolysis of the epididymal fat pad and on blood lactate levels were also studied. In addition, its possible effects on digitalis and halothane-catecholamine arrhythmias would be studied at this time. Such procedures are clearly far removed from the clinical situation, and their justification is based on a series of assumptions, some of which may be regarded as very tenuous.

\section{Practolol}

By such procedures, a new beta blocking compound, practolol ('Eraldin', ICI), was discovered. This compound is cardio-selective and has no membrane-stabilizing properties. It also differs from propranolol in that it has a degree of intrinsic stimulant activity. Practolol has a half-life in man of $10 \mathrm{hr}$ compared with $2 \mathrm{hr}$ for propranolol, and is minimally metabolized in man, whereas propranolol is extensively metabolized (Barrett et al., 1968; Dunlop \& Shanks, 1968; Fitzgerald \& Scales, 1968). Practolol has been undergoing clinical evaluation for some 2 years, and has already been shown to increase exercise tolerance in angina pectoris as well as to reduce the consumpton of glycerin trinitrate and the incidence of anginal pain. These observations are of considerable academic interest, since they confirm Black's original view that sympathetic activity may be deleterious to the heart of patients with angina pectoris. They also show that the membranestabilizing properties of propranolol are not necessary for its action in angina pectoris, since practolol is as effective as propranolol in increasing exercise tolerance, but does not have any local anaesthetic action (Wilson et al., 1969).

\section{Other clinical indications}

Clinical situations in which propranolol has been shown to be of value are given in the accompanying 
TABLE 1. Clinical indications in which beta-blockade has been used

\begin{tabular}{llll}
\hline \multicolumn{1}{c}{ Cardiac } & Endocrine & Central nervous & Other \\
\hline $\begin{array}{l}\text { Angina pectoris } \\
\begin{array}{l}\text { Arrhythmias } \\
\text { Hyper tension }\end{array}\end{array}$ & $\begin{array}{l}\text { Thyrotoxicosis } \\
\text { Phaeochromocytoma }\end{array}$ & Parkinsonism & Glaucoma \\
$\begin{array}{l}\text { Fyptots tetralogy } \\
\text { Hypertrophic obstructive cardiomyopathy }\end{array}$ & & Certain anxiety states \\
\hline
\end{tabular}

table. Black has indicated that none of these was predicted from the initial experimental studies in animals (Black, 1967). This indicates yet again the tremendous value of accurate clinical observation and feed-back of these observations to the laboratory as a guide for further research. However, Black did predict that beta-blockade might be of value in the cardiac arrhythmias associated with myocardial infarction, since it was already known that this was a situation associated with high concentration of catecholamines in an area of local tissue necrosis or anoxia. Such a situation is known to be potentially arrhythmogenic, and studies over the last 10 years have indicated the high incidence of cardiac arrhythmias following myocardial infarction. Initially, studies with propranolol indicated that it would control or reverse cardiac arrhythmias in myocardial infarction, but subsequent extensive study both with propranolol and oxprenolol show that if the drugs are given routinely to patients with myocardial infarction they have no effect on the morbidity or mortality associated with this condition (Sowton, 1968). These observations proved to be very disappointing, since there had been considerable hopes that the prophylactic administration of a betablocking drug might diminish the initial high mortality due to cardiac arrhythmias in myocardial infarction, because animal investigations had shown that beta-blockade would protect against ventricular arrhythmias in experimental myocardial infarction (Fearon, 1967; Pentecost \& Austen, 1966).

Myocardial infarction is associated with a state of high autonomic tone, and beta-blockade in this situation may affect the patient adversely for two reasons. Firstly, removal of sympathetic activity will permit vagal dominance of the heart, resulting in inappropriate cardiac slowing, a fall in cardiac output, hypotension and shock. The important role of the vagus in this situation has been demonstrated by Stannard, Sloman \& Sangster (1968), who gave atropine at the same time as propranolol, and prevented the unwanted haemodynamic sequelae. In addition, severely affected hearts may require increased sympathetic activity to maintain a satisfactory degree of myocardial contractility. Blockade of enhanced sympathetic activity in this situation may reduce myocardial contractility below a criticgl level. It seems, therefore, that the original laboratory predictions for beta-blockade in cardiac arrhythmiags associated with myocardial infarction have not been fulfilled. However, cardiac arrhythmias associated with anaesthesia, thyrotoxicosis, phaeochrom $\&$ cytoma, exercise and several other states, have been shown to respond favourably to beta-blocka\&e (Gibson \& Sowton, 1969). Recent studies with the cardio-selective beta-blocker, practolol, in postinfarction arrhythmias suggest that this compound may be of more value and safer to use in this particular situation, but much clinical study is yet te done before such a conclusion can be proven (Jewitt, Mercer \& Shillingford, 1969).

\section{Acknowledgments}

I have contributed little to the work described in the papew. Almost all of it has arisen from the studies of Dr A. Barrett, Dr J. Black, and especially Mr J. Thorp. Theirs is the work described in this paper, and I wish to express gratitude to them for making it so freely available to me.

\section{References}

Alleyne, G.O., Dickinson, C.J., Dornhurst, A.席, Fulton, R.N., Green, K.G., Hill, I.D., Hurst, R.' Lawrence, D.R., Pilkington, T., Prichard, B.N.C, RoBinson, B. \& RosenheIM, H.L. (1963) Effect of prä nethalol in angina pectoris. British Medical Jourral, 2, 1226.

Amsterdam, E.A., Wolfson, S. \& Gorlin, R. (1968) Effeet of therapy on survival in angina pectoris. Annals of Interigl Medicine, 68, 1151.

Apthorp, G.H., Chamberlain, D.A. \& Hayward, C. (1964) The effects of sympathectomy on the electrocardio gram and effort tolerance in angina pectoris. British Heass Journal, 26, 218.

Avoy, D., SwYRYd, E.A. \& Gould, R.G. (1965) Effects of $\alpha$ p-chlorophenoxyisobutyryl ethyl ester (CPIB), with a without androsterone on cholesterol biosynthesis in rat liver. Journal of Lipid Research, 6, 369.

BARRETT, A.M. (1969a) Mode of action of clofibrate relation to plasma free fatty acid. International Journgl of Clinical Pharmacology, Suppl. 1, 29.

BARRETT, A.M. (1969b) Management of coronary artegy disease. British Medical Journal, 1, 318.

Barrett, A.M., Crowther, A.F., Dunlop, D., Shanks, R.G. \& SMITH, L.H. (1968) Cardio-selective beta-blockadd. Archives of Experimental Pathology and PharmacologQ 259, 150. 
BLACK, J.W. (1967) The predictive value of animal tests in relation to drugs affecting the cardiovascular system in man. Drug Responses in Man (Ed. by C. Wolstenholme and R. Porter), pp. 113, 121-2. Churchill, Lcndon.

Black, J.W., DunCaN, W.A.M. \& Shanks, R.G. (1965) Comparison of some properties of pronethalol and propranolol. British Journal of Pharmacology, 25, 577.

BlaCK, J.W. \& StePhenson, J.S. (1962) Pharmacology of a new adrenergic beta-receptor blocking compound (Nethalide). Lancet, ii, 311.

British Medical Journal (1969) Management of coronary artery disease. British Medical Journal, $1,37$.

Chang, Y.H., Pinson, R. \& Malone, M.H. (1967) Displacement of L-thyroxine from its binding proteins in human, dog and rat plasma by $\alpha$ p-chlorophenoxyisobutyric acid. Biochemical Pharmacology, 16, 2053.

Dornhorst, A.C. \& Robinson, B.F. (1962) Clinical pharmacology of a new beta-adrenergic blocking agent (Nethalide). Lancet, ii, 314.

Duncan, L.J.P., Cullen, J.F., Iri land, J.T., Nolan, J., Clarke, B.F. \& Oliver, M.F. (1968) A three-year trial of Atromid therapy in exudative diabetic reinopathy. Journal of the American Diabetes Association, 17, 458.

Dunlop, D. \& ShANks, R.G. (1968) Selective blockade of adrenoceptive beta receptors in the heart. British Journal of Pharmacology, 32, 201.

FEARON, R.E. (1967) Propranolol in the prevention of ventricular fibrillation due to experimental coronary artery occlusion. Observations on its mode of action. American Journal of Cardiclogy, 20, 222.

Fitzgerald, J.D. (1960) Perspectives in adrenergic beta receptor blockade. Clinical Pharmacology and Therapeutics, 10, 292.

Fitzgerald, J.D. \& Scales, B. (1968) Effect of a new adrenergic beta blocking agent (ICI 50,172) on heart rate in relation to its blood levels. International Journal of Clinical Pharmacology, 1, 467.

Gianelly, RE., Goldman, R.H., Treister, B. \& Harrison, D.C. (1967). Propranolol in patients with angina pectoris. Annals of Internal Medicine, 67, 1216.

Gibson, D. \& Sowton, E. (1969) Beta adrenergic blocking drugs in dysrhythmias. Progress in Cardiovascular Diseases, $12,16$.

GinN, W.M. JR \& Orgain, E.S. (1966) Propranolol hydrochloride in the treatment of angina pectoris. Journal of the American Medical Association, 198, 1214.

Gorlin, R., Brackfeld, N., MACLeOd, C. \& Bopp, P. (1959) Effect of nitroglycerine on the coronary circulation in patients with coronary artery disease or increased left ventricular work. Circulation, 19, 705.

GRANDJEAN, T. (1967) The effect of adrenergic beta blockade in angina pectoris. Schweizerische Medizinische Wochenschrift, 97, 1559.

Harrison, M.T. \& HaRden, R.M.C.G. (1966) Some effects of clofibrate in hypothyroidism and on the metabolism of thyroxine. Scottish Medical Journal, 11, 213.

Hellmann, L., Zumoff, B., Kessler, G., Kara, E., Rubin, I.L. \& Rosenfeld, R.S. (1963) Reduction in cholesterol and lipids in man by ethenyl p-chlorophenoxyisobutyrate. Annals of Internal Medicine, 59, 477.

Hood, R., Bedding, F. \& Corlander, B. (1963) $\beta$ lipoprotein, lipoprotein lipase and Atromid. Journal of Atherosclerosis Research, 3, 509.
Jewitt, D.E., Mercer, C.J. \& Shillingford, J.P. (1969) Practolol in the treatment of cardiac dysrhythmias due to acute myocardial infarction. Lancet, ii, 227.

Katz, L.N. \& Stamler, J. (1953) Experimental Atherosclerosis. Thomas, Springfield, Illinois.

Lindgren, J. (1950) Angina pectoris. A clinical study with special reference to neurosurgical treatment. Acta Medica Scandinavica, Suppl. 243.

Mishkel, M.A. (1967) The diagnosis and management of the patient with xanthomatosis. An experience with thirty-five cases. Quarterly Journal of Medicine, 107, 141.

Mitchell, W.V., Truswell, A.S. \& Brontestewart, B. (1967) The effect of Atromid $S$ on faecal neutral steroids and bile acids. Progress in Biochemical Pharmacology, 2, 365.

Nestel, P.J., Hirsch, E.Z. \& Couzens, E.A. (1965) The effect of chlorophenoxyisobutyric acid and ethenyl estradiol on cholesterol turnover. Journal of Clinical Investigation, 44, 891.

OLIVER, M.F. (1963) Further observations on the effects of Atromid and of ethyl chlorophenoxyisobutyrate on serum lipid levels. Journal of Atherosclerosis Research, 3, 427.

OLIVER, M.F. (1967a) Control of hyperlipidaemia. In Recent Advances in Pharmacology and Therapeutics (Ed. by J. Fulton). Butterworth, London.

Oliver, M.F. (1967b) The present status of clofibrate. Circulation, 36, 337.

Pentecost, B.L. \& Austen, W.C. (1966) Beta adrenergic blockade in experimental myocardial infarction. American Heart Journal, 72, 790.

PlatT, D.S. \& ThORP, J.M. (1966) Changes in the weight and composition of the liver of the rat, dog and monkey treated with ethyl chlorophenoxyisobutyrate. Biochemical Pharmacology, 15, 915.

Powell, C.E. \& Slater, I.H. (1958) Blocking of inhibitory adrenergic receptors by a dichloro analogue of isoproterenol. Journal of Pharmacology, 122, 480.

Sowton, E. (1968) Beta-adrenergic blockade in cardiac infarction. Progress in Cardiovascular Diseases, 10, 561.

Stannard, M., Sloman, G. \& Sangster, L. (1968) The haemodynamic effects of atropine combined with propranolol in acute myocardial infarction. Medical Journal of Australia, 55, 333.

THORP, J.M. (196i) An experimental approach to the problem of disordered lipid metabolism. Journal of Atherosclerosis Reseaich, 3, 35.

ThORP, J.M. \& WARING, W.S. (1962) Modification of metabolism and distribution of lipids by ethyl chlorophenoxyisobutyrate. Nature, 194, 948.

Vaughan Williams, E.M. (1966) Mode of action of $\beta$ receptor antagonists on cardiac muscle. American Journal of Caldiology, 18, 399.

Westerfeld, W.W., Richert, D.A. \& Ruegamer, W.R. (1968) The role of the thyroid hormone in the effect of p-chlorophenoxyisobutyrate in rats. Bicchemical Pharmacology, 17, 1003.

Wilson, A.G., Brook, O.G., Lloyd, H.J. \& Robinson, B.F. (1969) Mechanism of action of $\beta$ adrenergic receptor blocking agents in angina pectoris: comparison of action of piopranolol with dexpropranolol and practolol. British Medical Journal, 4, 399. 